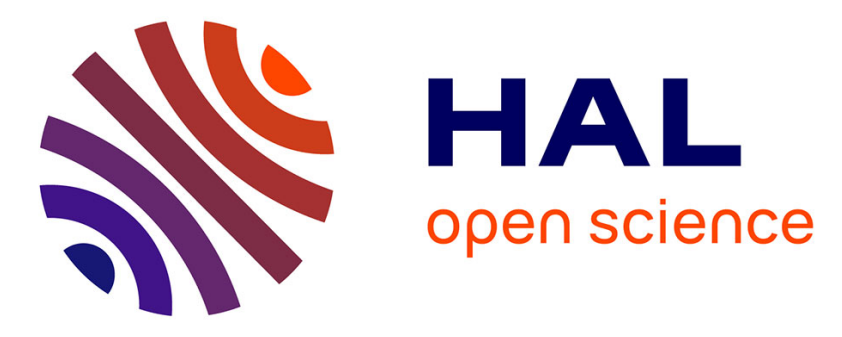

\title{
Effectiveness of Ranibizumab for Neovascular Age-related Macular Degeneration using Clinician Determined Retreatment Strategy
}

Anupma Kumar, Jayashree N Sahni, Alexandros N Stangos, Claudio Campa, Simon P Harding

\section{To cite this version:}

Anupma Kumar, Jayashree N Sahni, Alexandros N Stangos, Claudio Campa, Simon P Harding. Effectiveness of Ranibizumab for Neovascular Age-related Macular Degeneration using Clinician Determined Retreatment Strategy. British Journal of Ophthalmology, 2010, 95 (4), pp.530. 10.1136/bjo.2009.171868 . hal-00584830

\section{HAL Id: hal-00584830 \\ https://hal.science/hal-00584830}

Submitted on 11 Apr 2011

HAL is a multi-disciplinary open access archive for the deposit and dissemination of scientific research documents, whether they are published or not. The documents may come from teaching and research institutions in France or abroad, or from public or private research centers.
L'archive ouverte pluridisciplinaire HAL, est destinée au dépôt et à la diffusion de documents scientifiques de niveau recherche, publiés ou non, émanant des établissements d'enseignement et de recherche français ou étrangers, des laboratoires publics ou privés. 
Title

Effectiveness of Ranibizumab for Neovascular Age-related Macular

Degeneration using Clinician Determined Retreatment Strategy

Authors

A Kumar $^{1}$, JN Sahni $^{1}$, AN Stangos ${ }^{1}$, C Campa ${ }^{1}$, SP Harding ${ }^{1,2}$

Institutes

1. St Paul's Eye Unit, Royal Liverpool University Hospital, Liverpool, UK

2. Ophthalmology Research Unit, School of Clinical Sciences, University of Liverpool, UK

Address for correspondence

Mrs J Sahni

Consultant Ophthalmologist

St Paul's Eye Unit

Royal Liverpool University Hospital

Prescot St.

Liverpool, L7 8XP

UK

Email: jayashreesahni@yahoo.co.uk

Telephone Number: 01517063966

Key Words

age- related macular degeneration, Ranibizumab,

Word Count 2657 
The Corresponding Author has the right to grant on behalf of all authors and does grant on behalf of all authors, an exclusive licence (or non exclusive for government employees) on a worldwide basis to the BMJ Publishing Group Ltd to permit this article (if accepted) to be published in BJO and any other BMJPGL products and sublicenses such use and exploit all subsidiary rights, as set out in our licence.

Competing Interest: None declared. 


\section{Abstract}

Purpose: To report effectiveness of intravitreal Ranibizumab treatment for neovascular age-related macular degeneration (AMD) in a tertiary centre. Methods: One year prospective cohort study of patients with a diagnosis of neovascular AMD on fundus fluorescein angiography (FA) treated with Ranibizumab. Patients received treatment with 3 consecutive monthly treatments, followed by a clinician determined re-treatment strategy. Data collected included demographic details, baseline and subsequent follow-up visits, refraction protocol best corrected visual acuity (BCVA), contrast sensitivity (CS) and central foveal thickness (CFT) on optical coherence tomography.

Results: 81 patients were included in the study. The mean age was 79.5 years with a male:female ratio $32: 49$. The mean number of treatments was 5.6 ( $\pm 2.3 S D)$. Visual outcomes at 12 months showed $17.1 \%$ gained $\geq 15$ letters BCVA, $97.4 \%$ lost $<15$ letters and $2.5 \%$ lost $\geq 15$ letters. Mean change at 12 month were: BCVA +3.7 $( \pm 11.1)(p<0.01) ; C S+2.3( \pm 5.1)$ letters $(p<0.001), C F T$ $-100.1 \mu \mathrm{m}( \pm 111.9)(\mathrm{p}<0.001)$.

Conclusions: Clinician determined re-treatment after a three dose initiation phase appears to be less effective in improving BCVA than in randomised controlled trials. 


\section{Introduction}

Age-related macular degeneration (AMD) is a major cause of visual disability in the developed world.[1,2] The prevalence of AMD increases significantly with age, with neovascular (nAMD) having the slightly higher prevalence compared to geographic AMD.[3] Each year in the United Kingdom (UK) there are an estimated 26,000 new cases of nAMD.[4]

The introduction of Ranibizumab,[5] a recombinant humanised monoclonal antibody fragment that binds and effectively neutralises all active forms of vascular endothelial growth factor (VEGF), has heralded the introduction of a novel treatment of nAMD. However, treatment with anti-VEGF drugs requires regular intravitreal injections, which inevitably results in an increase on the demands of AMD services. The landmark randomised controlled trials, Minimally Classic/Occult Trial of the Anti-Vascular Endothelial Growth Factor Antibody Ranibizumab in the Treatment of Neovascular AMD (MARINA) and Anti-VEGF Antibody for the Treatment of Predominantly Classic Choroidal Neovascularization in AMD (ANCHOR), have reported high rates of stabilisation of vision and, for the first time, moderate rates of improvementt irrespective of lesion type.[6,7] A subsequent small open label, single centre non-randomised study, the Prospective Optical Coherence Tomography Imaging of Patients with Neovascular AMD Treated with intraOcular Ranibizumab (PrONTO) also showed similar results with fewer number of injections compared to the landmark studies.[8] Since its introduction there have been a small number of studies of 
Ranibizumab in routine clinical practice reporting the efficacy of different dosing regimes of Ranibizumab.[9-12]

In the UK, the National Institute for Clinical Excellence (NICE) approved the use of Ranibizumab as treatment for nAMD providing patients met the following criteria: visual acuity $6 / 12$ to $6 / 96$, lesion size $\leq 12$ disc diameter, recent disease progression and recommended treatment to be continued in those who demonstrate adequate response.[4] Patients with permanent structural damage are excluded. Based on the drug dosing regime presented by the manufacturer to the European Medicines Agency (EMEA) the NICE committee recommended that the majority of patients would require a mean of 8 injections in the first year and 6 injections in the second year in order to maintain vision. Eyes should receive an initial 3 dose initiation phases followed by clinician determined retreatment on a pro re nata (PRN) basis.[13]

The aim of our study was to determine if the results achieved in the randomised clinical trials (RCTs), could be translated into routine clinical practice applying the NICE recommendation. We present our 12 months clinical efficacy data of Ranibizumab from a single centre, evaluating best corrected visual acuity (BCVA), contract sensitivity (CS) and optical coherence tomography (OCT) mean central foveal thickness (CFT).

\section{Patient and methods}

We prospectively studied consecutive patients with treatment naïve nAMD commencing intravitreal Ranibizumab. Lesion components included were: classic 
and occult choroidal neovascularisation (CNV), RAP, blood, pigment epithelial detachment (PED), elevated blocked fluorescence, subretinal fluid (SRF). Inclusion criteria were: age > 50 years; baseline best corrected VA $\geq 25$ letters; nAMD lesions any component of which extended to within $200 \mu \mathrm{m}$ of the foveal centre ; signs of presumed recent disease progression in cases with occult or minimally classic lesions, as defined by recent loss of vision, new haemorhage and or an increase in lesion size on fluorescein angiography. Ethical approval for the research of clinical effectiveness of Ranibizumab in nAMD was obtained from the Liverpool Research Ethics Committee (LREC ref 02/051).

Full refraction protocol BCVA assessment was performed by externally accredited optometrists using the Early Treatment Diabetic Retinopathy Study (EDTRS) chart. BCVA was scored based on the total number of correct letters identified at $2 \mathrm{~m}$ plus 15 . If the patient read fewer than 20 letters at $2 \mathrm{~m}$, the patient was tested on the top 3 lines at $1 \mathrm{~m}$ and the score was the total number of letters read at $2 \mathrm{~m}$ plus the total number of letters read at $1 \mathrm{~m}$ and recorded at baseline, months 3, 6, 9 and 12 .

OCT scans were evaluated at every visit for presence or absence of intra-retinal fluid (IRF) and SRF. CFT was noted from the central reading on the map generated by the fast macular thickness protocol of the Stratus OCT (Zeiss, Germany). We evaluated the percentage of patients with CFT $>200 \mu \mathrm{m}$ at each time point since previous data on healthy eyes using the Stratus OCT (OCT3) has shown the CFT to be approximately $180 \pm 20 \mu \mathrm{m}$.[14] 
At these visits patients also had CS measurement on a Pelli-Robson chart at 1 meter with standardised illumination, fluorescein angiography (FA) and slit lamp fundus examination. In the interim visits BCVA, CFT and slit lamp examination were performed. For the purposes of this study we analysed data from baseline, months 3, 6, 9 and 12. Data were collected on number of intravitreal injections and complications. Baseline FAs were reviewed by externally accredited masked graders (Liverpool Reading Centre) to establish lesion characteristics for the purpose of analysis. CNV subtypes were categorised as classic with no occult, predominantly classic with occult, minimally classic without occult, minimally classic with occult, occult no classic and the presence of RAP lesion was also determined.

All patients were treated with monthly intravitreal $0.5 \mathrm{mg}$ Ranibizumab for the first 3 months. A set of crtieria were used to inform the retreatment decision making, but these were not prescriptive and the eventual decision to retreat was based on individual clinicans judgement (Table 1). Retreatment with Ranibizumab was considered if there was any deterioration in the signs and symptoms including drop in BCVA (5 to 19 letters from baseline), worsening of intra retinal or subretinal fluid, fresh haemorrhage or extension of lesion on FA. It was recommended that retreatment be avoided if there was no improvement in BCVA, there was persistent unresolving intraretinal and subretinal fluid, evidence of structural damage on OCT or there was an adverse event such as drop in BCVA by $>20$ letters. 
Table 1. Criteria used to guide clinician in re-treatment decision making.

\begin{tabular}{|c|c|c|}
\hline & Consider re-treatment & Consider no treatment \\
\hline Patient symptoms & Worse & - Better / no change \\
\hline BCVA & $\begin{array}{l}\text { Between } 5 \text { to } 19 \text { letter } \\
\text { loss from previous visit }\end{array}$ & $\begin{array}{ll}- & <5 \text { letter loss from } \\
& \text { previous visit } \\
\text { Or } & \\
- & \geq 30 \text { letters lost from } \\
& \text { baseline }\end{array}$ \\
\hline Fresh haemorrhage & Present & \\
\hline Subretinal fluid & Present & $\begin{array}{l}\text { - } \text { absent } \\
\text { - persistent but } \\
\text { unresponsive to } \\
\text { previous treatments }\end{array}$ \\
\hline Intraretinal fluid & $\begin{array}{l}\text { Present and worsening } \\
\text { with drop in BCVA }\end{array}$ & - absent \\
\hline $\begin{array}{l}\text { Structural damage on } \\
\text { OCT }\end{array}$ & & - present \\
\hline & & \\
\hline
\end{tabular}




\begin{tabular}{|l|l|l|}
\hline Fibrosis & & $\begin{array}{l}\bullet 75 \% \text { of the lesion and } \\
\text { involving the fovea }\end{array}$ \\
\hline FA & $\begin{array}{l}\text { extension and / or } \\
\text { leakage }\end{array}$ & \\
\hline Serious adverse events & & - present \\
\hline
\end{tabular}

BCVA = best corrected visual acuity

$\mathrm{FA}=$ fluorescein angiogram

In patients with clinical evidence of irreversible damage with no potential benefit from continuing treatment a decision was taken to suspend further intervention. Statistical analysis of the data was performed using SPSS for Windows version 12.0 (SPSS INC, Chicago, IL, USA). Data analysis was performed using descriptive statistics and paired sample t-test.

\section{Results}

81 patients were recruited: mean age 79.5 years (range 61-95), 32 male, 45 left eyes. 3 had bilateral involvement: for these patents data from the first eye treated were used for analysis. All patients received initial 3 consecutive monthly intravitreal 0.5mg Ranibizumab injections except one patient who underwent cataract surgery after the second injection and received no further injections over the 12 month period. 2 patients died during the study period but data was available up to month 3 and 6 respectively. A further 3 patients were lost to follow 
up after the initial 3 loading doses. Frequencies of lesion subtype at baseline ( $n=69)$ were: $34 \%$ classic no occult, $22 \%$ predominantly classic, $9 \%$ minimally classic with occult, $4 \%$ minimally classic CNV without occult, $19 \%$ occult no classic, $12 \%$ RAP.

The mean number of intravitreal Ranibizumab treatments was 5.6 ( $\pm 2.3 \mathrm{SD})$. At 12 months ( $n=76$ ) $97.4 \%$ lost $<15$ letters, $78.9 \%$ lost $<5$ letters, $17.1 \%$ gained $\geq 15$ letters BCVA and $73.7 \%$ of patients did not lose any vision (ie $\geq 0$ ). 2 patients lost >15 letters; one case each of severe subretinal haemorrhage secondary to a retinal pigment epithelial rip and of foveal atrophy.

Mean BCVA (letters \pm SD) at each study time point (Figure 1) was: baseline 49.5 \pm 13.4 , 3 month $54.2 \pm 14.1,6$ month $54.8 \pm 14.8,9$ month $52.3 \pm 15.2$ and 12 month $52.6 \pm 16.3$. Mean changes in BCVA (letters $\pm \mathrm{SD}$ ) for each time point and significance from baseline were: 3 month $7.4 \pm 5.7(p<0.005), 6$ month $5.2 \pm 10.2$ $(p<0.005), 9$ month $2.9 \pm 10.5(p<0.01), 12$ month $3.7 \pm 10.8(p<0.01)$. Subgroup analysis at 12 months showed a mean change in BCVA of $+6.9,+5.6,+6.7$ and +8.9 letters for classic no occult, predominantly classic with no occult, occult and RAP lesions respectively. Minimally classic with occult showed a mean decrease in BCVA of -0.6 and minimally classic without occult had a mean loss of -15 . Grouping into predominantly classic lesion characteristics and minimally classic or occult showed a mean improvement in BCVA of +6.6 and +1.65 letters respectively. Mean BCVA (letters \pm SD) baseline for predominantly classic lesion was $52.13 \pm 13.02$ and $50 \pm 12.7$ for and minimally classic or occult lesions. 
Mean contrast sensitivity (letters \pm SD) increased from $24.1 \pm 6.9$ at baseline to $26.4 \pm 7.9$ at 12 months $(+2.3 \pm 5.1)(p<0.001)$.The mean CS at each study time point is shown in Figure 2.

Mean CFT ( $\mu \mathrm{m} \pm \mathrm{SD}$ ) at baseline and subsequent study time points 3, 6, 9 and 12 months were as follows; $347( \pm 102), 231( \pm 80), 248( \pm 102), 251( \pm 89)$ and 246 ( \pm 107$)$. Frequencies of eyes with CFT $>200 \mu \mathrm{m}$ were: baseline $95.1 \%$, 3 months 51.9\%, 6 months $49.4 \%, 9$ months $63.0 \%$ and 12 months $56.8 \%$. At 12 months CFT reduced from baseline by $-100.1 \mu \mathrm{m}( \pm 111.9)(\mathrm{p}<0.001)$.

In this cohort of patients we had one adverse event of raised intraocular pressure which was treated with intravenous acetazolamide and resolved with no secondary vascular occlusion or impact on vision.

\section{Discussion}

In this study we have presented our one year data of Ranibizumab for treatment naïve CNV secondary to AMD and RAP lesions from a single tertiary centre. Mean BCVA improved by 3.7 letters at 12 months. $97.4 \%$ eyes lost $<15$ letters and $17.1 \%$ gained $\geq 15$ letters. Subgroup analysis found patients with RAP lesions had the biggest gain in BCVA at 8.9 letters. There was one patient with a rip of the RPE resulting in severe visual loss and one case of raised intraocular pressure. No other serious ocular adverse effects related to intravitreal injections were noted during the study period. 
In the MARINA and ANCHOR trials patients had a mean improvement of 7.2 and 11.3 letters at 12 months respectively $[6,7]$ compared to a mean gain in BCVA of 3.7 letters in our study overall. MARINA and ANCHOR evaluated minimally classic and predominantly classic types of lesion respectively. Our subgroup analysis based on baseline lesion characteristics showed a bigger gain in BCVA for predominantly classic lesions compared to minimally classic lesions (6.6 letters and 1.65 letters). Although both groups showed a mean improvement in BCVA, our results did not show the same level of improvement demonstrated in the landmark trials (6.6 versus 11.3 and 1.65 versus 7.2 letters). Also only $17.5 \%$ of our patients gained $\geq 15$ letters at 12 months as opposed to $35-40 \%$. This may be because patients received monthly intravitreal Ranibizumab injections regardless of the stage of the disease or the response to treatment. We did however find that a similar proportion of patients maintained acuity at the end of the study period when compared to results from the RCTs. Improvement in CS in our study was similar to that achieved in MARINA and ANCHOR. Approximately $97 \%$ patients lost $<15$ letters at 12 months in our study compared to $95 \%$ in MARINA and ANCHOR.[6-7]

In the PrONTO study patients underwent 3 consecutive monthly injections and additional treatment was given if the following criteria were met: 5 letter loss in vision, presence of fluid at the macula detected by OCT, $\geq 100 \mu \mathrm{m}$ increase in central retinal thickness (CRT); new-onset CNV; new macular haemorrhage; or persistent macular fluid detected by OCT. Patients in the PrONTO study achieved similar outcomes in visual acuity (mean improvement in BCVA was 9.2 letters and $35 \%$ patients gained $>15$ letters) as MARINA and ANCHOR with 
fewer numbers of injections (mean 5.6 injections). This suggested that flexible OCT guided re-treatment could sustain visual gain. The OCT results of the MARINA study also show a close correlation of foveal thickness and response to Ranibizumab therapy.[15] Although our study had a similar treatment protocol to the PrONTO study we were not able to demonstrate the same level of improvement in visual acuity despite equivalent number of treatments. Both studies included all subtypes of CNV but in the PrONTO study majority of the eyes had minimally classic lesion (57.5\%) as opposed to our cohort of patients in whom the majority had a predominantly classic lesion (56\%). Interestingly in our study lesions with minimally classic or occult only characteristics did not show a good visual outcome.

Recent clinical studies by Rothenbuehler et al. and Cohen et al. reported a mean improvement of 7.3 and 0.7 letters respectively. In comparison to Rothenbuehler et al. our study does not demonstrate the same level of improvement but we did find maintenance of vision in a higher proportion of our patients ( $97.4 \%$ our study compared to $61 \%$ Rothenbuehler et al). In terms of study designs it is difficult to compare these studies due to different cohort of patients and treatment regimes. Rothenbuehler et al. have included patients with similar age and baseline vision to our study but the use of stricter inclusion and re-treatment criteria may have influenced their results. Some of the differences in the re-treatment guidelines between our studies were a) use of sub-RPE fluid on OCT and b) using metamorphopsia on the Amsler grid as indicators for re-treatment, whereas we stopped treatment if there was evidence of persistent IRF or SRF unresponsive to treatment.[11] 
In comparison to Cohen et al. our favourable result may be partially attributed to the monthly follow-up visits at our centre which effectively results in the better monitoring of disease activity. In other clinical studies visual outcome data has been reported using different vision charts and the use of conversion techniques limit comparison of. $[9,12]$

In the PrONTO study the mean CFT was $394 \mu \mathrm{m}$ at baseline and $216 \mu \mathrm{m}$ at 12 months. In our cohort mean CFT reduced from $347( \pm 102) \mu \mathrm{m}$ to $246( \pm 107) \mu \mathrm{m}$ at 12 months. The maximum drop was at the 3 month visit. There was no statistically significant correlation between CFT and BCVA. However, there was a slight increase in the number of patients with CFT $>200 \mu \mathrm{m}$ at the 9 month visit corresponding to the drop in vision. CFT was noted from the fast macular thickness map on the Stratus OCT. Errors of retinal boundary and thickness measurements are frequent with the OCT analysis and segmentation algorithms were reported in $92 \%$ of eyes in a previous study by Sadda et al. and others.[16] This could have influenced the readings in our study. The scans were reviewed for the presence of IRF, SRF and PED to inform our decision to retreat. This may have resulted in under treatment of the patients at the interim visits when the decision to retreat was based on OCT parameters. OCT scans cannot be used in isolation as predictor of disease activity. As noted in a recent study the resolution of fluid is not always correlated with improvement in vision.[9] Previous studies have also suggested that leakage on FA may not collect as fluid on OCT (especially Stratus OCT).[17] 
There are some limitations to our study. Presence of co-existing ocular pathology or time to treatment from first diagnosis has not been taken into consideration and may have contributed to our results.[18] Strict inclusion and exclusion criteria utilised in RCTs cannot be adhered to in routine clinical practise. This inevitably results in differences between the study populations, which may affect the final outcome and limit translation of results achieved in RCTs. However we believe that our results give a good estimate of the efficacy of the protocol we used applicable to routine clinical care as defined in at least one national guideline.

In conclusion, our results show that a 3 monthly treatment initiation phase followed by PRN treatment was associated with rates of stabilisation and maintenance of vision as good as the landmark RCTs. However, this regime achieved in our hands only half of the rates of improvement in vision by 3 lines or more seen in the RCTs. Statistically significant improvements in retinal morphology and improvement in CS were also seen. Guidelines for retreating patients outside RCTs need to be established and further data is required to determine a treatment regime, which provides clinical, economic and practical effectiveness. 


\section{References}

1 Klein R, Klein BE, Linton KL. Prevalence of age-related maculopathy: the Beaver Dam Eye Study. Ophthalmology. 1992;99:933-943.

2 Vingerling JR, Dielemans I, Hofman A, et al. The prevalence of age-related maculopathy in the Rotterdam study. Ophthalmology. 1995;102:205-210.

3 Bressler NM, Bressler SB, Fine SL. Age-related macular degeneration. Surv Ophthalmol. 1988;32:375-413. 
4 National Institute for Clinical Excellence. Macular degeneration (age-related) ranibizumab and pegaptanib. Technology appraisals TA 155;August2008.

5 Ferrara N, Damico L, Shams N, et al. Development of Ranibizumab, an antivascular endothelial growth factor antigen binding fragment, as therapy for neovascular age-related macular degeneration. Retina. 2006;26:859-870.

6 Rosenfeld PJ, Brown DM, Heier JS, et al. Ranibizumab for neovascular agerelated macular degeneration. N Engl J Med. 2006;355:1419-1431.

7 Brown DM, Kaiser PK, Michels M, et al. Ranibizumab versus verteporfin for neovascular age-related macular degeneration. N Engl J Med. 2006;355:14321444.

8 Fung AE, Lalwani GA, Rosenfeld PJ, et al. An OCT guided, variable dosing regimen with intravitreal Ranibizumab (Lucentis) for neovascular age-related macular degeneration. Am J Ophthalmol. 2007;143:566-583.

9 Dadgostar H, Ventura AA, Chung JY, et al. Evaluation of injection frequency and visual acuity outcomes for Ranibizumab monotherapy in exudative agerelated macular degeneration. Ophthalmology. 2009;116:1740-1747.

10 Cohen SY, Dubois L, Tadayoni R, et al. Results of one-year's treatment with Ranibizumab for exudative age-related macular degeneration in a clinical setting. Am J Ophthalmol. 2009;148:409-413. 
11 Rothenbuehler SP, Waeber D, Brinkman CK, et al. Effects of Ranibizumab in patients with subfoveal choroidal neovascularization attributable to age-related macular degeneration. Am J Ophthalmol. 2009;147:831-837.

12 Michalova K, Wickremasinghe SS, Tan TH et al. Ranibizumab treatment for neovascular age-related macular degeneration; from randomized trials to clinical practice. Eye. 2009;23:1633-1640

13 European Public Assessment Report (EPAR); Lucentis summary for the public: $\mathrm{EMEA} / \mathrm{H} / \mathrm{C} / 715$ http://www.emea.europa.eu/humandocs/PDFs/EPAR/lucentis/H-715-en1.pdf (accessed 06 September 2009)

14 Chan A, Duker J, Ko TH, et al. Normal macular thickness measurements in healthy eyes using stratus optical coherence tomography. Arch Ophthalmol. 2006;124:193-198 15 Kaiser PK, Blodi BA, Shapiro H, et al. Angiographic and Optical Coherence Tomographic Results of the MARINA Study of Ranibizumab in Neovascular AgeRelated Macular Degeneration. Ophthalmology. 2007;114:1868-1875

16 Sadda SR, Wu Z, Walsh AC, et al. Errors in retinal thickness measurements obtained by optical coherence tomography. Ophthalmology. 2006;113:285-293. 
17 Sahni J, Stanga P, Wong D, et al. Optical coherence tomography in photodynamic therapy for subfoveal choroidal neovascularisation secondary to age related macular degeneration: a cross sectional study. Br J Ophthalmol. 2005;89:316-320.

18 Arias L, Armada F, Donate $\mathrm{J}$ et al. Delay in treating age-related macular degeneration in Spain is associated with progressive vision loss. Eye. 2009;23:326-333.

\section{Legends}

Table 1 Criteria used to guide clinicians in their decision to retreat after the initial loading dose.

Figure 1 Mean best corrected visual acuity at each time point.

This graph illustrates the best corrected visual acuity using the Early Treatment Diabetic Retinopathy Study chart recorded as number of letters read at 1 meter plotted against baseline, months 3, 6, 9 and 12 .

\section{Figure 2 Mean contrast sensitivity at each time point.}

This graph illustrates the contrast sensitivity measurements recorded as number of letters read using the Pelli-Robson chart at 1 meter plotted against baseline, months 3, 6, 9 and 12 . 

n.

no.

ti.

is

E

है

है

$\alpha$

है

4

$-7$

c

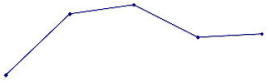




$$
\text { xes. }
$$
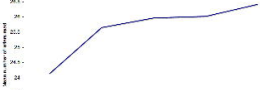

$$
24 .
$$

225

$$
\text { ascates thots }
$$

kens 6

ibto:

Wertis

คpนจ 2 